\title{
Short and Long Term Energy Storage for Enhanced Resilience of Electric Infrastructures Storage of Compressed Hydrogen and Oxygen Gasses Derived From Electrolysis to Provide Grid Connected Mechanical and Electrochemical Electrical Power Generation on Demand
}

DC Grant

University of Washington Tacoma, dcgrant@uw.edu

Follow this and additional works at: https://digitalcommons.tacoma.uw.edu/tech_pub

\section{Recommended Citation}

Grant, D. (2014). Short and long term energy storage for enhanced resilience of electric infrastructures storage of compressed hydrogen and oxygen gasses derived from electrolysis to provide grid connected mechanical and electrochemical electrical power generation on demand. Presented at the 2014 5th International Renewable Energy Congress (IREC), Hammamet, Tunisia. https://doi.org/10.1109/IREC.2014.6826953 


\title{
Short and Long Term Energy Storage for Enhanced Resilience of Electric Infrastructures
}

\author{
Storage of Compressed Hydrogen and Oxygen Gasses Derived from Electrolysis to Provide \\ Grid Connected Mechanical and Electrochemical Electrical Power Generation on Demand.
}

\author{
Dennis Charles Grant - CISSP, CISM, IEEE Member \\ Master Infrastructure Planning and Management Candidate \\ National Science Foundation Cyber Corps Scholarship for Service Recipient \\ Center for Information Assurance and Cybersecurity \\ University of Washington, Seattle, WA, USA \\ and \\ Cyber Security Instructor \\ Computer Science Department \\ Columbia Basin College, Pasco, WA, USA
}

\begin{abstract}
Energy storage based upon converting electricity from water to hydrogen gas provides a solution to the problem of intermittency in renewable energy systems. These benefits are not specific to isolated solar and wind energy production but can also be derived as a complement to load and demand variations on the fully integrated electrical grid. The main components of this system are electrolytic cells, which use electricity to generate hydrogen and oxygen from water, compressed gas hydrogen and oxygen storage tanks and fuel cells, which recombine hydrogen with oxygen to generate electricity.

At times of excess energy availability, electrolytic cells are used as a controllable load by which the excess energy is converted into hydrogen and oxygen gas. When there is insufficient energy to meet demands, the fuel cell is used to recombine hydrogen and oxygen into water and create electricity. Water storage and compressed gasses can be used to further tune the load. Water can be pumped from one reservoir to another to create artificial demand, and can be allowed to flow by gravitational power to create electricity on demand. Compressed gasses can similarly be managed to create load or increase generation capacity at will. These complements are key to effectively managing electrolytic cell arrays for maximum potential, but also provide for very high versatility and resilience of the system, which can allow operators to micro-manage electrical supplies and demands. This work examines the technical details of such systems and extracts some of the lessons learned from more than fifty years of related research, prototyping and implementations.
\end{abstract}

Keywords - electrolysis; fuel cell; hydrogen; energy storage.

\section{INTRODUCTION}

It is widely accepted that the electrolysis of water was developed to produce hydrogen in the late 1700's and very early 1800's. In 1839, Sir William Grove described experiments to generate electricity by supplying hydrogen and oxygen to electrodes. (Savett, 2000) (Smithsonian Institution, 2013). Though initial fuel cells were successful in creating electricity, they were not very efficient and did not provide cost-effective electrical generation.
Since that time, many important developments have made electrolysis and fuel cell technology much more efficient and therefore economically sound. As could reasonably be expected, technological advances in reaction materials and the related processes have provided the greatest advantages. External environmental and economic developments have been just as important however, in making these technologies more feasible and reasonable.

There are many examples of electrolytic hydrogen generation implementations for energy storage from all over the world. A representative sampling is being offered here, in no particular order of importance. These technological applications are of various sizes and designs. Most of the examples have been coupled with wind or photovoltaic power production systems, but this coupling is not a requisite strategy for success.

There is likewise considerable body of research and experimentation performed on the electrolysis, hydrogen storage, hydrogen adsorption and recombination of hydrogen and oxygen in fuel cells to create electricity. A comprehensive analysis of related experimentation would also be impractical. Several examples of breakthroughs involved are highlighted. This work lists many interesting developments which have independently improved the economic viability of hydrogen production, storage and electrical generation methods.

\section{EARLY DEVELOPMENT}

As mentioned previously, the underlying technologies were initially discovered and implemented well over 150 years ago. A hundred years after Sir William Grove; Francis Thomas Bacon built a cell that used nickel gauze electrodes, alkali electrolyte and operated under pressure. By 1958, his designs using potassium hydroxide $(\mathrm{KOH})$ were reliable enough to attract the attention of Pratt \& Whitney, who licensed Bacon's work for sale to the National Aeronautics and Space Administration for use on the Apollo spacecraft, (Smithsonian Institution, 2013). 
For the purpose of this discussion, the concept of early development will include advancements made between 1955 and 1975. Though several advancements were made during this era by a handful research teams; engineers at Oklahoma State University in Stillwater Oklahoma led the charge in design, testing and implementation of solar and wind powered electrical generation, coupled with the electrolysis of water, storage of hydrogen and recombination with oxygen in the fuel cell to meet diurnal and seasonal demand variations. These efforts in Electrical and Energy Systems Engineering by Drs. William L. Hughes, H. Jack Allison, and Rama G. Ramakumar were foundational with respect to combining these discrete systems to create a clean and renewable hybrid system which provided for the storage of energy derived from intermittent sources.

These early works include the 1963 publication: "An Energy System for the Future," which evaluated various storage methods and explored the use of hydrogen-oxygen fuel cells as a complement to unconventional energy sources (including wind and solar power), (Hughes, 1963). This short but informative paper, includes the first block diagram for an integrated system, including electrolysis and fuel cells for the conversion of renewable energy sources into hydrogen gas, for long term storage and generation of electricity independent of supply. It further introduces a 100 watt model system then under production. The modularity and scalability of such a system was even then seen as a huge advantage.

Later documents from this era include considerable experimental data based on multiple implementations and continued experimentation. By the time "Prospects for Tapping Solar Energy on a Large Scale" and "Solar Energy Conversion and Storage Systems for the Future" were published, the advantages of storing energy as hydrogen created by electrolysis was already very clearly documented as the subject of "considerable research at OSU since 1961". These papers also discuss production and operation of a $10 \mathrm{~kW}$ system, (Ramakumar, 1974) (Ramakumar, 1975).

The OSU mechanisms for electrolysis considerably lowered the costs using high pressure implementations at moderate temperatures, to eliminate the requirement of noble metals for catalyst. Milled nickel fins were a key enabling efficiencies in excess of $90 \%$ to be obtained. Even at this early juncture, cost considerations appeared to be very favorable in comparison to nuclear and coal generation facilities, (Ramakumar, 1974).

Although pervasive adoption of the combined technologies has lagged far behind the somewhat optimistic expectations of these engineers, this work laid a foundation for other researchers and implementations. Considerable further experimentation to reduce the costs and increase the efficiency of electrolysis and fuel cells have built upon the experimentation and research of these pioneering energy systems engineers.

\section{INVESTIGATIONS AND IMPLEMENTATIONS}

There are a large number of implementation examples and cost-benefit investigations for these technologies which have taken place in many diverse parts of the world. Though comprehensive analysis is impractical, this work presents a handful of representative examples of such systems. This small sampling of projects represents the great diversity of sizes and approaches that have been taken.
In addition to the systems designed and constructed in Stillwater, Oklahoma, referenced works include: A 350kW solar hydrogen demonstration plant operated in Saudi Arabia and producing 463 cubic meters at normal pressure $(\mathrm{N} \mathrm{m} 3)$ of hydrogen per day since 1993, (Almogren, 2004). A 43kW system operating since 1994 in Jurlich, Germany, (Ghosh, 2003). A $5 \mathrm{~kW}$ system producing $0.33 \mathrm{~N} \mathrm{~m} 3$ of hydrogen per day in Madrid, Spain, (Chaparro, 2005). A variable input, $34 \mathrm{~kW}$ electrolysis system implemented in 2006 in Leicestershire, United Kingdom, that is capable of producing $8 \mathrm{~N} \mathrm{~m} 3$ per hour, (Little, 2007). A $2.7 \mathrm{~kW}$ system installed in Cuernavaca, Mexico that produces 1500 liters of hydrogen per hour at normal pressure, (Arriaga, 2007). An 8kW system in Xanthi, Greece, (Ipsakis, 2009). A $2 \mathrm{~kW}$ system in Milan, Italy producing 18.6 $\mathrm{N} \mathrm{m} 3$ per year. (Leva, 2009) and, a small test-bed system in Badajoz, Spain in 2009 which utilizes a metal hydride storage mechanism, (Calderón, 2010).

Nearly all of the findings and lessons learned in these examples were identical, despite the large variations in components and the scale of these systems. All of these systems were found to be very safe, stable and reliable. Very little maintenance was required for continued high performance of the systems. The systems show no signs of wear or reduction in efficiency over the relatively short life of these studies. Literally all of the researchers are in agreement: the use of electrolytic cells to produce hydrogen and subsequent use of fuel cells to provide electrical power is "a viable, efficient and promising alternative for energy storage," (Calderón, 2010).

Many researchers agree that efficiency gains and cost reductions in electrolytic cells are likely to provide the greatest advantages for improvement of the overall efficiency and costeffectiveness of the system as a whole. Active management of the systems can also enable higher overall efficiency. No reviewed implementation made use of compressed gas or water storage systems for load levelling or power production. The use of such complementary power sources provides an important overall improvement in operational efficiency that should not be overlooked or minimized.

When analyzing the inputs and outputs from these experimental systems, one must be careful to separate efficiency flaws inherent in intermittent power production mechanisms from the effectiveness of the storage and retrieval mechanisms. Every one of the example systems studied has based important aspects of design upon the use of solar or wind power production. Although some of these systems were grid connected, the intention of all of them was to provide selfsufficiency in power production and storage. There are huge advantages in designing a hydrogen storage system to be fully integrated with the electrical grid. These advantages have been overlooked in most related works.

Though an analysis of economic viability of these systems will be conducted later, it should be noted that very large amounts of potential energy generation capacity is wasted due to lack of demand at the time generation is available. Grid connected storage is critically important to overall efficiency and resilience of the electrical grid. 


\section{MATERIALS EXPERIMENTATION}

It would be literally impossible for a short study like this one to discuss all of the material advancements and process experimentation made in these areas. Advancements in component materials and reaction efficiency continue at a rapid pace. To remain focused on the best return for technological advancements, the current work concentrates on the electrolysis of water as the area where most cost reduction and efficiency gains can aid the overall system in being more lucrative. Although advancements have certainly been made in hydrogen storage mechanisms, including the understanding and use of metal hydrides for hydrogen storage directly in solid metals, (Pukazhelvan, 2012), many researchers agree that improving electrolysis directly improves the economic viability and reduces the payback period for capital investment. Costs can certainly also be reduced in fuel cell materials and some consideration is given to viable and less expensive alternative materials for the chemisorption process used to facilitate the hydrogen reaction with oxygen to form water and electricity.

Considerable research has been completed in the last ten years on materials and processes to improve the efficiency of electrolysis. The traditional use of noble metals was eliminated by the time of early development efforts at Oklahoma State University, where the designs incorporated pure nickel fins for the electrolytic process anode and cathode. Advancements in the late 1970's included the use of nickel iron alloys which improved gassing, and nickel sulfur alloys which increased the surface area of the electrodes mainly due to effects of bulging and rippling on the surfaces and therefore increased reactivity.

More recent research to improve electrolytic efficiency has fallen largely in two different realms. One trend has been toward experimentation with more exotic alloys to improve gassing characteristics. The other trend has been to experiment with higher pressure and temperature electrolysis to increase process efficiencies. Both of these research directions have been very successful. Although the success of each of these two camps has been impressive, there was no evidence found of attempts to combine the effectiveness of more effective alloys with higher temperature reactions. Such a combination is clearly an area for further research in improved reaction efficiency.

In 2003 there were a handful of experiments which increased the temperature and altered the materials used in electrolysis. For example, the use of solid polymer electrolytes were found to be most effective at around 490 degrees Celsius. The use of Iridium oxide for example was found to be more effective at the oxygen electrode in conjunction with platinum at the hydrogen electrode, (Rasten, 2003). The use of cobalt and molybdenum as electrocatalytic activators were also introduced in 2003, with fairly significant effect. Gains in efficiency of more than $10 \%$ were derived, just by including the substances in the reactive process. (Stojić, 2003).

At about the same time, designs for high temperature electrolysis began to be more common. The Department of Energy started a research and development initiative to work on high-temperature electrolysis which was largely focused on hydrogen production as a cohabitant of nuclear energy. Idaho National Engineering and Environmental Laboratories, (INEEL) was one of the many interested parties, and performed several very promising studies and experiments related to the use of a steam-hydrogen mixture along with solid oxide electrolytic cells. The INEEL system piloted a $500 \mathrm{~kW}$ demonstration facility capable of achieving 2780 liters per minute at normal temperature $(\mathrm{N} 1 / \mathrm{min})$, but anticipated developing a 5MW facility in the 2013 timeframe, (Herring, 2003) (Idaho National Labs, 2003).

Though there was a great deal of success in improving efficiency using complex electrocatalysts in 2004; there was little overall improvement related to materials costs as an outcome of this work, and stability of the reactant system may have actually been decreased due to the extreme increase in surface area of reactants such as the exotic iridium, ruthenium, tantalum oxides which provided an amazing 94\% electrolytic cell efficiency, (Marshall, 2004).

Plans for high temperature electrolysis, based on thermonuclear reactions continued during this time under the guidance of the US Department of Energy. It appears that there were a great many beneficial and productive studies undertaken as part of the research and development plan for nuclear produced hydrogen, but much of this seems to have been classified. Other than initial plans and reports, subsequent reports and developments were not found in the public domain, (Herring, 2003) (Idaho National Labs, 2003) (Department of Energy, 2004).

The DOE program was admirable for insight and foresight, but fell victim to a common misconception related to hydrogen power. Over many years of research, there has been a great deal of investigation and experimentation focused on replacing petroleum as the commonly used fuel for motorized vehicles. Huge amounts of effort has been focused on hydrogen as the fuel of the future. Although hydrogen could eventually lend itself to become a transportation fuel, its greatest strength is currently as a storage medium. Research into use as a transportation fuel has actually served to diminish the conception of hydrogen as a valuable fuel stock for electrical storage.

The 2007 and 2008 timeframe also exhibited important improvements in both high temperature electrolysis and separate improvements in cathode materials. Japanese researchers published interesting results related to steam electrolysis in solid oxide electrolytic cells in conjunction with a nuclear reactor, (Fujiwara, 2008), while a Korean team increased overall efficiency by $46 \%$ using a very high temperature gas-cooled reactor, (Shin, 2007). During the same timeframe, nickel sulfur and manganese (Ni-S-Mn) alloy electrodes were proven by Chinese researchers to provide higher electrochemical activity with increased stability in potassium hydroxide solution. This alloy exhibited the best stability and largest exchange current density in comparison to other nickel alloys being tested. (Shan, 2008).

Between 2010 and 2013 however, many further studies were performed related to the electrolysis of water. Further studies of ionic activators like cobalt and molybdenum in the electrolyte, (Nikolic, 2010) as well as study of cobalt and tungsten activated electrodes (Kaninski, 2011) and nickel molybdenum coated electrodes (Kaninski, 2011) all pointed to individualized $20 \%$ plus gains in efficiency. During this time, high temperature steam electrolysis with solid oxide systems saw continued success of experiments in China. (Bo, 20-10) (Zhang, 2013). 
Also in 2013, a new type of alkaline electrochemical cell was developed using nickel foam instead of the alloy electrodes or metallic meshes used previously. This foam electrolytic cell was paired with high pressure and high temperature processes to yield a very high efficiency process, stated as $98.7 \%$ electrical efficiency at 240 degrees Celsius and 37 bar of pressure. (Allebrod, 2013).

Though more experimentation with alloy variations and higher temperature steam electrolysis used in combination are undoubtedly warranted; it is clear that highly efficient electrolytic processes have currently come of age. The next two years should witness the merge of these two research realms and a very highly effective electrolytic process enable very costeffective hydrogen production.

\section{ECONOMIC VIABILITY}

The economic viability of hydrogen production and hydrogen energy storage has consistently been the subject of inquiry. In every era since the early development of these technologies, there are been active supporters and detractors. Most criticisms revolved around the costs of implementation. But unfortunately many research endeavors have completely missed the mark. Most research has directly coupled hydrogen production to stand-alone solar and wind power projects. A very large amount of investigation has focused on hydrogen as a transportation fuel. These efforts have effectively diluted the public and academic understanding of the viability of hydrogen.

As with experimentations and implementations, there have likewise been a substantial number of economic analyses of hydrogen as a potential fuel in literally every era at least since the 1960's. Most of these analyses has been both glowing and forward looking; citing a short timeframe to the viability of hydrogen as a fuel. Though none of the authors can be criticized for a lack of realistic calculations or expectations, none of them could either be expected to foresee the future.

Despite such consistent endorsements of hydrogen energy, the world has yet to see widespread adoption of hydrogen production and use. Of course, a great part of that lack of adoption is the prevalence of fossil fuels and their continued dominance in world economic and energy markets. It will certainly be very difficult to displace such a profitable and convenient energy source. The very profitable companies that currently dominate world energy markets are certainly one force opposing change in the realm of energy production and storage.

A handful of economic analyses are considered herein for perspective. Most of these considerations have included solar power sources as part of their assessment. Though this inclusion does not invalidate the results, it must be noted as a nuance which is detrimental to profitability.

Lodhi's work in late 1988, "Collection and Storage of Solar Energy," made a comparison of several potential storage mechanisms for solar power. At the time, this work should have been considered quite comprehensive. His conclusions were that 'When all factors are taken into consideration, hydrogen... is the most cost effective energy carrier.” (Lodhi, 1989).

Subsequent studies of economic viability in Spain and Egypt found that hydrogen production was both economically viable and strategically advantageous to both these country's economies, (Contreras, 1999) (Abdallah, 1999). In 2001, Yang lauded the use of hydrogen as a versatile and highly effective storage medium for energy, (Yang, 2001).

In 2003 the return on investment for a photovoltaic driven system with common electrolytic technology, hydrogen storage and fuel cell recombination ability was determined to have a very substantial return on investment beginning around 15 to 16 years. This analysis pointed to the most profitable scenario being a grid connected system. This system was expected to cost some 7.8 million euros and would return 6.6 million euros in profit during its sixteenth and twentieth year of operation. Although fifteen years is a considerable amount of time to wait for profitability, it must be noted that the most expensive and least profitable portion of this system was the photovoltaic array. (Vidueira, 2003).

In 2005, Barbir's analysis of the production of hydrogen from electrolysis found that it was only marginally economically feasible. But Barbir's study focused only on technologies which were fully developed and available during the 1990's. Even so, he determined that the high cost of photovoltaics and electrolytic cells were the main factors which marginalized such systems to remote areas and special applications. The advances already made at the time of this study in the efficiency and lower cost of electrolytic cells, coupled with the current lower cost per unit of photovoltaics, invalidate these results in the current time. (Barbir, 2005).

Similarly, a French study in 2007 determined that the cost of electrolysis caused hydrogen production to be unprofitable. This study however based the concept of profitability on the sale of hydrogen and instability of market price projections. It further made assumptions based on traditional designs for electrolysis which are much more expensive and less efficient than existing technologies. This is another example of missing the mark in hydrogen use. (Floch, 2007).

University of Ontario faculty performed an economic analysis related to hydrogen storage in 2011. In it, they analyzed two wind farms near Ontario (at $189 \mathrm{MW}$ and $490 \mathrm{MW}$ capacity respectively). This study is important due to the resulting calculations, and because it analyzes data related to the unused capacity of many diverse generation facilities in the Ontario area. Notwithstanding the use of very conservative numbers, and the premature capping of the expected lifetime of the overall system at twenty years, they found this type of implementation to be economically viable. As with other investigations, this study also used expensive and inefficient commercially available electrolytic cells. Yet, profitability was conservatively determined to be found in about the sixteenth or seventeenth year of operation for these installations. (Ozbilen, 2012).

\section{DECOUPLING FROM RENEWABLE INPUTS}

Though the vast majority of hydrogen storage systems have been developed in conjunction with renewable energy projects for remote locations, there is currently no reason to treat this approach as the only option. At the end of 2012 wind energy production in the United States alone exceeded 60 Gigawatts. Literally all of this wind power is directly connected into the existing electrical grid. 
There is no reason to consider hydrogen production as tied to a windmill or photovoltaic array and no advantage to consider hydrogen solely as a transportation fuel. Hydrogen storage is, in fact, best suited to a fully connected electrical grid and is most efficiently utilized in a comprehensive and multifaceted system. Such a system can be tuned in many ways to balance load and demand, and to make the best use of modern control systems to maintain high efficiency and effectiveness of its components.

The use of water and compressed gas to provide on demand load and supply is one example of enhanced controls which can drastically improve efficiencies. Control systems for monitoring and predicting loads, demands and reactions are also critically important for high levels of efficiency and profitability of such systems over time, (Contreras, 2007) (Valenciaga, 2010).

Coupling hydrogen storage with distribution networks and collocating them with variable output generation has also proven effective in improving profitability. The use of newly developed alloys and steam electrolysis methods can drastically reduce the pay-back period from fifteen years to well under ten, when such a system is actively monitored and managed.

A hydrogen energy storage system is ideally suited to coupling with the electric grid. Most utilities spend considerable time and effort in balancing load to demand, as well as trading excess supply to other utilities to optimize system performance. Considerable amounts of excess potential are often wasted due to a lack of immediate demand.

Grid connected systems have huge advantages over standalone systems. The economic viability of a remote system in integrally tied to the costs and effectiveness of the power generation mechanism. Expensive solar panels and windmills drastically alter the return on investment equation.

\section{CONCLUSIONS}

Hydrogen production systems coupled with the existing electrical infrastructure offer the best economic and environmental advantages available in energy storage to date. Recent advancements have rapidly elevated electrolysis and fuel cells to being the most efficient process available for long-term energy storage. A well designed facility with strong infrastructural systems connectivity offers the most effective location for hydrogen production and storage operations. Grid connectivity provides for system efficiencies which have largely been overlooked in previous analyses.

Although there is room for further experimentation to combine high temperature and pressure 'steam' electrolysis with the latest developments in electrode alloys, we have already reached the point of viability and profitability for these technologies.

A sufficiently large amount of unused or excess electrical generation capacity exists at this time. Any type of energy storage would be considered helpful and even potentially necessary for efficient operations of the electrical grid as a whole. Coupling the wasteful nature of intermittent generation resources with a fairly efficient hydrogen storage process is a critical step toward resilience and overall viability of electrical systems in general. The technologies discussed in this paper are continually being enhanced and further developed, but they are sufficiently mature to warrant installation now.

\section{ACKNOWLEDGMENT}

This work was performed with the support of the National Science Foundation, through the Cyber Corps Scholarship for Services Program administered by the University of Washington Center for Information Assurance and Cybersecurity.

Grateful appreciation is extended to Dr. Sam Chung, Endowed Professor of Information Systems and Security, Director of Cyber Physical Systems for the Center for Information Assurance and Cybersecurity, and Dr. Barbara Endicott-Popovsky, Director of the Center for Information Assurance and Cybersecurity and the Academic Director for the Master of Infrastructure Planning and Management program, for their highly valued insights, enduring support and mentorship.

\section{REFERENCES}

[1] M. A. H Abdallah, S. S. Asfour and T. N. Veziroglu, "Solar-Hydrogen Energy System for Egypt," International Journal of Hydrogen Energy, Volume 24, pp. 505-517, 1999. 12/2013: http://www.sciencedirect.com/science/article/pii/S0360319998001086

[2] F. Allebrod, C. Chatzichristodoulou and M. B. Mogensen, "Alkaline Electrolysis Cell at High Temperature and Pressure of $250^{\circ} \mathrm{C}$ and 42 Bar," Journal of Power Sources, Volume 229, pp. 22-31, May 2013. 12/2013: http://www.sciencedirect.com/science/article/pii/S0378775312017806

[3] H. J. Allison, "A New Approach to High-Pressure, High-Temperature HydrogenOxygen Fuel-Cell and Electrolysis-Cell Design," Proceedings of the Third Annual Conference on Energy Conversion and Storage, October 1965, pp. 4-1 to 4-11. 1967.

[4] H. J. Allison, R. Ramakumar and W. L. Hughes "Economic High-Pressure Hydrogen-Oxygen Regenerative Fuel-Cell Systems," Proceedings of the Fourth Intersociety Energy Conversion Engineering Conference (IECEC), pp. 1042 -1047, 1969.

[5] S. Almogren and T. N. Veziroglu, "Solar-Hydrogen Energy System for Saudi Arabia," International Journal of Hydrogen Energy, Volume 29, Issue 11, pp. 1181-1190, Sept. 2004. 12/2013: http://www.sciencedirect.com/science/article/pii/S036031990300332X

[6] L.G. Arriaga, W. Martínez, U. Cano and H. Blud, "Direct Coupling of a SolarHydrogen System in Mexico," International Journal of Hydrogen Energy, Volume 32, pp. 2247-2252, 2007. 12/2013: http://cat.inist.fr/?aModele $=$ afficheN $\&$ cpsidt $=19070643$

[7] F. Barbir, "PEM Electrolysis for Production of Hydrogen from Renewable Energy Sources," Solar Energy, Volume 78, Issue 5, pp. 661-669, May 2005. 12/2013: http://www.sciencedirect.com/science/article/pii/S0038092X04002464

[8] Y. Bo, Z. Wenqiang, X. Jingming and C. Jing, "Status and Research of Highly Efficient Hydrogen Production through High Temperature Steam Electrolysis at INET," International Journal of Hydrogen Energy, Volume 35, Issue 7, pp. 28292835, 2010. Retrieved Dec. 2013 from:

http://www.sciencedirect.com/science/article/pii/S036031990900706X

[9] S. O. Brauser and W. L. Hughes. "A Proposed Hydrogen-Oxygen Power Cycle," Proceedings of the Second Intersociety Energy Conversion Engineering Conference (IECEC), pp. 809 -811, 1967.

[10] M. Calderón, A.J. Calderón, A. Ramiro, and J.F. González, "Weather Data and Energy Balance of a Hybrid Photovoltaic-Wind System with Hydrogen Storage," Tenth Chinese Hydrogen Energy Conference, International Journal of Hydrogen Energy, Volume 35, pp. 7706-7715, 2010. 12/2013: http://www.sciencedirect.com/science/article/pii/S0360319910010190

[11] A.M. Chaparro, J. Soler, M.J. Escudero, E.M.L. de Ceballos, U. Wittstadt and L. Daza, "Data Results and Operational Experience with a Solar Hydrogen System," Journal of Power Sources, Volume 144, Issue 1, pp. 165-169, June 2005. 12/2013: http://www.sciencedirect.com/science/article/pii/S0378775305000169

[12] A. Contreras, R. Guirado and T.N. Veziroglu, "Design and simulation of the power control system of a plant for the generation of hydrogen via electrolysis, using photovoltaic solar energy," International Journal of Hydrogen Energy, Volume 32, Issue 18, pp. 4635-4640, 2007. 12/2013: http://www.sciencedirect.com/science/article/pii/S0360319907004193 
[13] A. Contreras, J. Carpio, M. Molero, and T.N Veziroglu, "Solar-Hydrogen an Energy System for Sustainable Development in Spain," International Journal of Hydrogen Energy, Volume 24, Issue 11, pp. 1041-1052, November 1999. 12/2013: http://www.sciencedirect.com/science/article/pii/S0360319998001347

[14] Department of Energy, "Nuclear Hydrogen R\&D Plan," Department Of Energy, Office of Nuclear Energy, Science and Technology, March 2004. 12/2013: http://www.hydrogen.energy.gov/pdfs/nuclear_energy_h2_plan.pdf

[15] P.H. Floch, S. Gabriel, C. Mansilla, and F.Werkoff, "On the Production of Hydrogen via Alkaline Electrolysis During Off-Peak Periods," International Journal of Hydrogen Energy, Volume 32, pp. 4641-4647, 2007. 12/2013: http://www.sciencedirect.com/science/article/pii/S0360319907004193

[16] S. Fujiwara, S. Kasai, H. Yamauchi, K. Yamada, S. Makino, K. Matsunaga, M. Yoshino, T. Kameda, T. Ogawa, S. Momma and E. Hoashi, "Hydrogen Production by High Temperature Electrolysis with Nuclear Reactor". Progress in Nuclear Energy. Volume 50, Issues 2-6, pp. 422-426, March-August 2008. 12/2013: http://www.sciencedirect.com/science/article/pii/S0149197007001709

[17] J. C. Ganley, "High Temperature and Pressure Alkaline Electrolysis," International Journal of Hydrogen Energy, Volume 34, Issue 9, pp. 3604-3611, May 2009. 12/2013:

http://www.sciencedirect.com/science/article/pii/S0360319909003577

[18] P.C. Ghosh, B. Emonts, H. Janßen, J. Mergel and D. Stolten, "Ten Years of Operational Experience with a Hydrogen-Based Renewable Energy Supply System," Solar Energy, Volume 75, Issue 6, pp. 469-478, December 2003. 12/2013: http://www.sciencedirect.com/science/article/pii/S0038092X03003414

[19] Gregory, D.P., "Fuel Cells," Mills and Boon, Ltd., London, 1972.

[20] G. Giannakoudis, Athanasios I. Papadopoulos, P. Seferlis and S. Voutetakis, "Optimum Design and Operation Under Uncertainty of Power Systems Using Renewable Energy Sources and Hydrogen Storage," International Journal of Hydrogen Energy, Volume 35, Issue 3, February 2010, pp. 872-891, 2010. 12/2013: http://www.sciencedirect.com/science/article/pii/S0360319909018138

[21] S. Herring, R. Anderson, J. O'Brien, P. Lessing, and C. Stoots, "Development of a High Temperature Solid Oxide Electrolyser System," Idaho National Engineering and Environmental Laboratory, 2003 Hydrogen and Fuel Cells Merit Review Meeting, Berkeley, CA, May 20, 2003. 12/2013: http://wwwl.eere.energy.gov/hydrogenandfuelcells/pdfs/merit03/40 inel j stephe n herring.pdf

[22] Hine, Fumio, "Electrode Prodcesses and Electrochemical Engioneering", New York, Plenum Press, 1985.

[23] W. L. Hughes, C. M. Summers and H. J. Allison, "An Energy System for the Future," IEEE Transactions on Industrial Electronics, pp.108 -111 1963. 12/2013: $\mathrm{http}: / /$ ieeexplore.ieee.org $/ \mathrm{xpl} / \operatorname{login} . j \mathrm{sp}$ ?tp $=\&$ arnumber $=5409083$

[24] Idaho National Engineering and Environmental Laboratory, "High-Temperature Electrolysis for Hydrogen Production from Nuclear Energy," Idaho National Engineering and Environmental Laboratory, Idaho Falls, Idaho, 2003. 12/2013: http://purl.access.gpo.gov/GPO/LPS103495

[25] D. Ipsakis, S. Voutetakis, P. Seferlis, F. Stergiopoulos and C. Elmasides, "Power Management Strategies for a Stand-Alone Power System Using Renewable Energy Sources and Hydrogen Storage," International Journal of Hydrogen Energy, Volume 34, Issue 16, August 2009, pp. 7081-7095, 2009. 12/2013: http://www.sciencedirect.com.offcampus.lib.washington.edu/science/article/pii/S0 360319908007027

[26] S. Leva and D. Zaninelli, "Hybrid Renewable Energy-Fuel Cell System: Design and Performance Evaluation," Electric Power System Research, Volume 79, pp. 316-324, 2009. 12/2013: http://www.sciencedirect.com/science/article/pii/S0378779608001983

[27] M. Little, M. Thompson and D. Infield, "Electrical Integration of Renewable Energy into Stand-Alone Power Supplies Incorporating Hydrogen Storage," 12/2013:

http://www.sciencedirect.com.offcampus.lib.washington.edu/science/article/pii/S0 360319906005209

[28] M.A.K. Lodhi, "Collection and Storage of Solar Energy," International Journal of Hydrogen Energy, Volume 14, Issue 6, Pages 379-411, 1989. 12/2013: http://www.sciencedirect.com.offcampus.lib.washington.edu/science/article/pii/03 60319989901687\#

[29] M. P. M. Kaninski, S. M. Miulovic, G. S. Tasic, A. D. Maksic, and V. M. Nikolic, "A Study on the Co-W Activated Ni Electrodes for the Hydrogen Production from Alkaline Water Electrolysis - Energy Saving," International Journal of Hydrogen Energy, Volume 36, Issue 9, pp. 5227-5235, May 2011. 12/2013: http://www.sciencedirect.com/science/article/pii/S0360319911003922

[30] M. P. M. Kaninski, D. P. Saponjic, V. M. Nikolic, D. L. Zugic and G. S. Tasic, "Energy Consumption and Stability of the Ni-Mo Electrodes for the Alkaline Hydrogen Production at Industrial Conditions," International Journal of Hydrogen Energy, Volume 36, Issue 15, pp. 8864-8868, July 2011. 12/2013: http://www.sciencedirect.com/science/article/pii/S0360319911010111
[31] A.T. Marshall, S. Sunde, M. Tsypkin and R. Tunold, "Performance of a PEM Water Electrolysis Cell Using Electrocatalysts for the Oxygen Evolution Electrode," International Journal of Hydrogen Energy, Volume 32, Issue 13, pp. 2320-2324, September 2007. 12/2013: http://www.sciencedirect.com/science/article/pii/S0360319907001140

[32] V.M. Nikolic, G. S. Tasic, A. D. Maksic, D. P. Saponjic, S. M. Miulovic, and M. P. M. Kaninski, "Raising Efficiency of Hydrogen Generation from Alkaline Water Electrolysis - Energy Saving," International Journal of Hydrogen Energy, Volume 35, Issue 22, pp. 12369-12373, November 2010. 12/2013: http://www.sciencedirect.com/science/article/pii/S0360319910017088

[33] A. Ozbilen, I. Dincer, G.F. Naterer and M. Aydin, "Role of Hydrogen Storage in Renewable Energy Management for Ontario," International Journal of Hydrogen Energy, Volume 37, pp. 7343-7354, 2012. 12/2013: http://www.sciencedirect.com/science/article/pii/S0360319912001231

[34] D. Pukazhselvan, V. Kumar, and S.K. Singh, "High Capacity Hydrogen Storage: Basic Aspects, New Developments and Milestones," Nano Energy, Volume 1, Issue 4, July 2012, pp. 566-589, 2012. 12/2013: http://www.sciencedirect.com /science/article/pii/S2211285512001115

[35] R. Ramakumar, "An experimental Hydrogen-Oxygen Regenerative Fuel Cell," Proceedings of the Frontiers of Power Technology Conference, p. 18-11, 1968.

[36] R. Ramakumar, Allison, H. J.; Hughes, W.L., "Prospects for Tapping Solar Energy on a Large Scale," Solar Energy, Volume 16, Issue 2, October 1974, Pages $107-$ 115, 1974. 12/2013:

http://www.sciencedirect.com.offcampus.lib.washington.edu/science/article/pii/00 38092X74900061

[37] R. Ramakumar, Allison, H. J.; Hughes, W.L., "Solar Energy Conversion and Storage Systems for the Future," IEEE Transactions on Power Apparatus and Systems, vol.94, no.6, pp.1926 - 1934, Nov. 1975. 12/2013: http://ieeexplore.ieee.org.offcampus.lib.washington.edu/stamp/stamp.jsp?tp=\&arn umber $=1601640$

[38] R. Ramakumar, "Storage options for harnessing wind energy," Journal of Mechanical Engineering, 1983. Retrieved Oct. 2013 from: http://www.osti.gov/scitech/servlets/purl/6926897

[39] E. Rasten, G. Hagen, and R. Tunold, "Electrocatalysis in Water Electrolysis with Solid Polymer Electrolyte," Electrochimica Acta, Volume 48, Issues 25-26, pp. 3945-3952, November 2003. 12/2013: http://www.sciencedirect.com/science/article/pii/S0013468603005334

[40] S. C. Savett, "The Characterization of New Fluorinated Ionomers for use in Polymer Electrolyte Membrane (PEM) Fuel Cells," Clemson University Doctoral Dissertation, Chapter One: An Introduction to Fuel Cells, 2000. 12/2013: http://savett.com/about/introduction-chapterl.pdf

[41] Z. Shan, Y. Liu, Z. Chen, G. Warrender, and J. Tian, "Amorphous Ni-S-Mn Alloy as Hydrogen Evolution Reaction Cathode in Alkaline Medium," International Journal of Hydrogen Energy, Volume 33, pp. 28 - 33, 2008. 12/2013: http://www.sciencedirect.com/science/article/pii/S0360319907005150

[42] Y. Shin, W. Park, J. Chang and J. Park, "Evaluation of the High Temperature Electrolysis of Steam to Produce Hydrogen," International Journal of Hydrogen Energy, Volume 32, Issues 10-11, pp. 1486-1491, July-August 2007. 12/2013: http://www.sciencedirect.com/science/article/pii/S0360319906005088

[43] Smithsonian Institution, "Fuel Cells," National Museum of American History, 2013. 12/2013: http://americanhistory.si.edu/fuelcells/index.htm

[44] D. L. Stojić, M. P. Marčeta, S. P. Sovilj, and Š. S. Miljanić, "Hydrogen Generation from Water Electrolysis-Possibilities of Energy Saving," Journal of Power Sources, Volume 118, Issue 1, pp. 315-319, 2003. 12/2013: http://www.sciencedirect.com/science/article/pii/S0378775303000776

[45] F. Valenciaga and C.A. Evangelista, "Control Design for an Autonomous Wind Based Hydrogen Production System," International Journal of Hydrogen Energy, Volume 35, pp. 5799-5807, 2010. 12/2013: http://www.sciencedirect.com/science/article/pii/S0360319910003964

[46] J. M. Vidueira, A. Contreras and T.N. Veziroglu, "PV Autonomous Installation to Produce Hydrogen Via Electrolysis, and Its Use in FC Buses," International Journal of Hydrogen Energy, Volume 28, Issue 9, pp. 927-937, 2003. 12/2013: http://www.sciencedirect.com/science/article/pii/S036031990200191X

[47] W. Yang and O. Aydin, "Wind Energy-Hydrogen Storage Hybrid Power Generation," International Journal of Energy Research, Volume 25, Issue 5, pp. 449-463, John Wiley \& Sons, Ltd., April 2001. 12/2013: http://onlinelibrary.wiley.com/doi/10.1002/er.696

[48] H. Zhang, S. Su, X. Chen, G. Lin and J. Chen, "Configuration Design and Performance Optimum Analysis of a Solar-Driven High Temperature Steam Electrolysis System for Hydrogen Production," International Journal of Hydrogen Energy, Volume 38, Issue 11, pp. 4298-4307, April 2013. 12/2013: http://www.sciencedirect.com/science/article/pii/S0360319913003315 